\title{
Maternal foraging trip duration as a population-level index of foraging and reproductive success for the northern fur seal
}

\author{
Greg B. Merrill ${ }^{1,2, *}$, J. Ward Testa ${ }^{3}$, Jennifer M. Burns ${ }^{4,2}$ \\ ${ }^{1}$ Duke University Marine Laboratory, Duke University, Beaufort, NC 28516, USA \\ ${ }^{2}$ Department of Biological Sciences, University of Alaska Anchorage, Anchorage, AK 99507, USA \\ ${ }^{3}$ National Marine Mammal Laboratory, Alaska Fisheries Science Center/National Marine Fisheries Service/NOAA, Seattle, \\ WA 98115, USA \\ ${ }^{4}$ Present address: Department of Biological Sciences, Texas Tech University, Lubbock, TX 79409, USA
}

\begin{abstract}
The duration of maternal foraging trips has been regarded as an indicator of foraging conditions in many marine mammals, including northern fur seals Callorhinus ursinus (NFS). However, previous work has focused on individual variation, was conducted during limited portions of the lactation period, and/or reached conclusions based on relatively small sample sizes. Here, we build upon the substantial foundations of this previous work to establish maternal foraging trip duration (MFTD) as an index of foraging success at the rookery level. We found that a $1 \mathrm{~d}$ increase in rookery-averaged MFTD corresponded to a $6.52 \%$ reduction in the average mass of female pups. Furthermore, rookery-averaged MFTD increased by $0.34 \mathrm{~d}$ per $1{ }^{\circ} \mathrm{C}$ increase in average ocean bottom temperature. The magnitude of variation observed in both MFTD and pup mass is likely too small to help explain the general decline in population size seen over recent decades. However, the correlation between rookery-averaged MFTD and pup mass highlights the potential power of the MFTD index to detect bottom-up effects on pup growth, a likely indicator of survival. Furthermore, when compared with concurrently conducted studies on prey distribution, availability, and quality, the relationship between MFTD and bottom temperature suggests a northward shift in distribution of NFS preferred prey, walleye pollock Gadus chalcogrammus, that is associated with an increase in trip duration across the study period. Thus, rookery-averaged MFTD is a promising metric for tracking broad environmental changes, such as northerly shifts in the Eastern Bering Sea cold pool.
\end{abstract}

KEY WORDS: Pup mass $\cdot$ Northern fur seal $\cdot$ Callorhinus ursinus $\cdot$ Walleye pollock $\cdot$ Gadus chalcogrammus $\cdot$ VHF telemetry $\cdot$ Bering Sea $\cdot$ Pribilof Islands

\section{INTRODUCTION}

Like other otariids, maternal northern fur seals Callorhinus ursinus (NFS) employ a central-place foraging strategy, in which they alternate foraging trips to sea in support of milk production with brief suckling bouts ashore (Orian \& Pearson 1979, Gentry \& Holt 1986, Gentry 1998, Sterling 2009). The largest population of NFS occupies the Pribilof Islands (St.

${ }^{*}$ Corresponding author: gregory.merrill@duke.edu

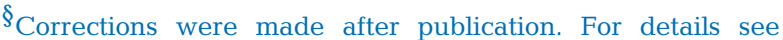
www.int-res.com/articles/meps_oa/m670p247.pdf

This corrected version: July 22, 2021
George [STG] and St. Paul [SNP] Islands), Alaska (USA), during the summer, breeding on 1 of 19 rookeries. Many studies have linked maternal foraging trip duration (MFTD) of otariids to direct and indirect measures of prey availability and/or abundance, as well as to the environmental conditions known to influence prey abundance (e.g. Boyd et al. 1994, Merrick \& Loughlin 1997, Boyd 1999, Beauplet et al. 2004, Sterling 2009, Kuhn et al. 2015). Additionally, several

( ) The authors 2021. Open Access under Creative Commons by Attribution Licence. Use, distribution and reproduction are unrestricted. Authors and original publication must be credited.

Publisher: Inter-Research · www.int-res.com 
studies have linked increased MFTD to reductions in pup growth rates (Springer et al. 2008), the latter of which is a likely indicator of post-weaning survival. For example, Antarctic fur seals Arctocephalus gazella from Bird Island, South Georgia, demonstrated longer MFTDs, low pup weights (Croxall \& Prince 1979, Doidge et al. 1984b) and increased mortality in 1978 (Doidge et al. 1984a), likely as a result of low local availability of krill as observed by both researchers and commercial vessels that season (Doidge et al. 1986). Increased sea surface temperatures caused by the $2015 \mathrm{El}$ Niño resulted in increased foraging effort by adult California sea lions Zalophus californianus and Guadalupe fur seals A. townsendi followed by significant declines in California sea lion pup mass (Elorriaga-Verplancken et al. 2016). Similarly, the San Miguel Island population of NFS in California (USA) periodically experiences reduced prey availability caused by El Niño events, resulting in longer MFTD and decreased pup growth (DeLong \& Antonelis 1991).

Foraging trip durations have also been correlated with the distances between rookeries and foraging grounds. For example, MFTDs for the Pribilof population of NFS are nearly 3 times longer than MFTDs for females from Bogoslof Island, AK, due primarily to the longer distances that Pribilof females must travel to reach foraging grounds. This increased travel time is thought to be the cause of comparatively reduced pup weights on the Pribilof Islands (Springer et al. 2008). This echoes findings for other central-place foragers, including seabirds and other otariids, in which adults that must travel further distances to forage spend more time away from their offspring, resulting in lower offspring growth rates (e.g. Boyd 1999, Saraux et al. 2011, MassardierGalatà et al. 2017). Benoit-Bird et al. (2013) examined the patchiness of forage fish distribution in relation to NFS movements and concluded that time spent within forage patches by fur seals was relatively constant within each trip, and that variation in MFTD was largely a function of transit times to and from the source rookery, and between forage patches. However, many otariid studies have largely focused at the level of the individual, during limited portions of the lactation period, and/or with small sample sizes. Here we build upon these studies to test whether average MFTD at the rookery level can be used as a broad-scale index of fur seal foraging and reproductive success related to the conditions of the surrounding foraging environment.

Across taxa, demography is related to foraging performance via reproduction and survival (Clutton-
Brock et al. 1982, Grant \& Grant 2002, Weimerskirch 2018). Fitness, i.e. self-maintenance and the ability to reproduce, is determined by how efficiently resources are extracted from the environment. Thus, widespread poor individual fitness can lead to population declines and may be monitored via indices of foraging success. The Pribilof Island population of NFS in Alaska has declined by $51 \%$ overall since 1998 at an annual rate of $3.4 \%$ (Towell et al. 2019), with spatiotemporal variation by island. While the underlying cause remains elusive despite decades of study, low pup growth rates have been suggested as a cause of this population decline (Kuhn et al. 2019). We hope examining relationships between the spatial and temporal differences in MFTD and covariates similarly partitioned can help identify possible cause(s) of the population decline. For example, if rookery-averaged pup mass varies significantly between rookeries and across years in the manner predicted based on previously established links with MFTD and environmental conditions, such a relationship would connote that a link may exist with rookeryspecific MFTD across the pup-rearing season and pup survival after weaning.

Telemetry studies tracking NFS movements have documented that females show strong specificity for foraging habitat based on the breeding rookery complex (a group of rookeries with similar diets and foraging areas) to which they belong (Robson et al. 2004, Gudmundson et al. 2006, Zeppelin \& Ream 2006, Call et al. 2008, Kuhn et al. 2014). These studies have revealed that females from rookeries on opposite sides of SNP Island have large, distinct, partially overlapping foraging grounds centered over the Bering Sea continental shelf (Robson et al. 2004, Zeppelin \& Ream 2006, Call et al. 2008), while those from STG rookeries have smaller foraging grounds that straddle the continental shelf margin (Robson et al. 2004, Zeppelin \& Ream 2006, Call et al. 2008). Differences in foraging grounds are reflected in female diets, which are broadly reflective of the relative composition and abundance of prey assemblages found in the hydrographic domains of the eastern Bering Sea (EBS) continental shelf and basin that females from each rookery complex use (Gudmundson et al. 2006, Zeppelin \& Ream 2006). For example, STG females rely more heavily on gonatid squid than do females from SNP Island (Zeppelin \& Ream 2006, Zeppelin \& Orr 2010), likely because squid are more common in the shelf margins. However, females from all Pribilof rookeries depend significantly (frequency of occurrence $\sim 43-84 \%$ ) on walleye pollock Gadus chalcogrammus (henreafter 'pollock') (e.g. Zeppelin 
\& Ream 2006, Zeppelin \& Orr 2010). Furthermore, NFS scat has revealed that age- 0 and age- 1 pollock are the most important component of female diet during the reproductive period (Zeppelin \& Ream 2006). Although Gudmundson et al. (2006) noted that scat samples were biased toward younger/smaller fish, underestimating the consumption of older/larger prey, and reliance on older age classes has occurred when younger age classes are less abundant (Kuhn et al. 2019). How a warming climate interacts with forage species abundance and availability has implications for NFS foraging behavior.

Sub-polar environments are among the most rapidly warming regions of the planet (Okkonen et al. 2004, Taylor et al. 2013, Walsh 2014, Stabeno \& Bell 2019, Thoman \& Walsh 2019), and changes in oceanographic temperatures have far-reaching implications for ecosystem dynamics as the distribution and abundance of marine life changes in response to temperature, currents, and seasonal patterns of ice formation, presence, and melt (Lotze et al. 2019). Stock assessments of pollock are routinely conducted in the Bering Sea via annual bottom trawl and biannual acoustic trawl surveys, which collect environmental data concurrently (Conner \& Lauth 2016, Ianelli et al. 2019, Siddon \& Zador 2019). Since 2014, the region has been characterized by unusually warm conditions, with above average bottom temperatures $\left(2.57 \pm 0.15^{\circ} \mathrm{C}, 1982-2019\right.$, except 2017 when temperatures were roughly average), where 2019 was the warmest yet on record (Ianelli et al. 2019, Stabeno \& Bell 2019). In 2018, there was a complete lack of a 'cold pool' (area defined by bottom temperatures below $0^{\circ} \mathrm{C}$ ) across the EBS shelf, which is important for structuring the EBS ecosystem (Mueter \& Litzow 2008). The cold pool stimulates lipid-rich trophic pathways that support recruitment of groundfish species, such as pollock (Sigler et al. 2016, Holsman et al. 2018). Additionally, the cold pool acts as a physical barrier to the north-south movement of some species, and is a determinant of relative strength between top-down versus bottom-up ecosystem controls (Sigler et al. 2016, Holsman et al. 2018). Body condition (length-weight residuals) of age-1 pollock declined, but remained positive during the warmer conditions seen between 2016 and 2017 (Siddon \& Zador 2019).

For this study, we tested the hypothesis that average MFTD as determined from large numbers of females at a given rookery is associated with differences in average pup mass, and is reflective of variation in the foraging conditions (prey abundance and/ or quality; water temperature) found within broad re- gions of the EBS. To achieve this goal, we used very high frequency (VHF) telemetry to monitor MFTD of a large number of female northern fur seals at 5 breeding rookeries across 3 breeding seasons and at 1 rookery across 9 breeding seasons. Considering the chronic decline in the Pribilof Islands NFS population in recent decades and ongoing climatic warming, successfully linking variability in rookery-averaged MFTD with pup mass, metrics of pollock prey resources, and environment (temperature) would support the use of rookery-averaged MFTD as a longterm monitoring tool for fur seals. NFS may respond to climate-induced changes in prey distributions, which can be explored by examining a suite of relationships between MFTD, bottom temperature, and measures of prey quantity and quality. For example, MFTD may increase as NFS pursue preferred prey northward. This would be supported by increases in bottom temperatures which are known to induce latitudinal shifts in pollock distribution northward (Kotwicki et al. 2005, Mueter \& Litzow 2008, Eisner et al. 2020) and declines in pup mass pursuant to increased fasting durations while the mother is away foraging. No relationship between abundance/biomass and MFTD would help to support the notion that prey distributions are shifting by demonstrating that prey quantity did not impact foraging behavior. Similarly, a lack of a relationship between energy density or body condition of prey with MFTD would further buttress claims regarding shifts in prey distribution by noting no impact of quality of prey on foraging behavior.

\section{MATERIALS AND METHODS}

\subsection{Ethics statement}

This work was authorized by the University of Alaska Anchorage Institutional Animal Care and Use Committee (animal handling protocol 944372) and the US National Marine Fisheries Service pursuant with the Marine Mammal Protection Act (permit no. 14327-01).

\subsection{Data collection and analysis}

\subsubsection{MFTD}

The attendance behavior of maternal animals was monitored using VHF radio telemetry. Sexually mature female northern fur seals (identified by verifying lactation) from 5 breeding rookeries (North, 


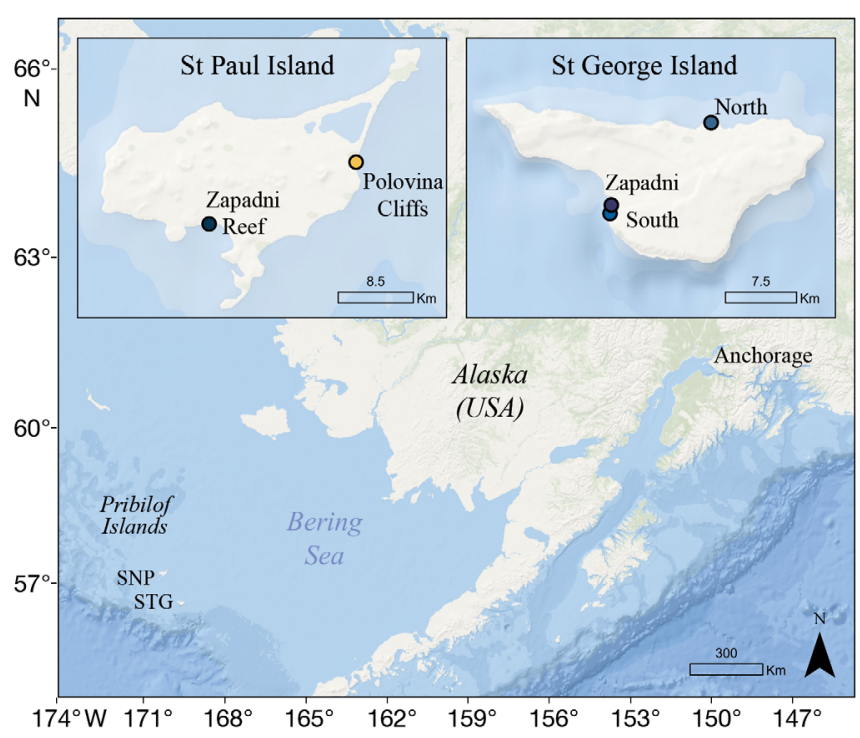

Fig. 1. Pribilof Islands, Alaska (USA), showing the locations of northern fur seal rookeries studied on St. George and St. Paul Islands (STG and SNP, respectively)

South, Zapadni, Polovina Cliffs, and Zapadni Reef) on the 2 Pribilof Islands (Fig. 1) were captured between 22 September and 6 October of 2011-2019. Tagging generally occurred by corralling 2 groups of females at locations roughly one-third and twothirds down the length of a rookery, helping to ensure that tagged individuals are representative of the entire population at a given rookery. Upon capture, females were weighed (see Tables S1 \& S2 in the Supplement, www.int-res.com/articles/suppl/m666 p217_supp.xlsx) and tagged with a VHF pulsecoded radio transmitter (Advanced Telemetry Systems) and an accompanying livestock tag (Allflex Livestock Identification System, www.allflexusa. com). The variation in number of tags deployed by rookery and year are provided in Table 1 . Transmitters, henceforth 'tags,' weighed $\sim 14 \mathrm{~g}$ and were applied to the trailing edge of a fore flipper using a pair of modified livestock tagging pliers. Pulse coding allowed for up to 25 tags to occupy each of 10 frequencies used, which permitted accurate detection of large numbers of individual females at each site. Duty cycle programs for tags, described in Table 2 , were chosen to maximize battery life, while effectively capturing various maternal attendance behaviors of the NFS for this and other studies.

Receiver-datalogger stations were erected at each of the 5 study rookeries to monitor the presence or absence of tagged adult females on the breeding rookery. Each station was equipped with either a Yagi or an omnidirectional antenna, a solar-charged marine
Table 1. Number of VHF transmitters attached to adult female northern fur seals by day of year and study rookery (see Fig. 1). STG: St. George Island; SNP: St. Paul Island

\begin{tabular}{|lcccc|}
\hline Island & Year & Rookery & $\begin{array}{c}\text { N tags } \\
\text { deployed }\end{array}$ & $\begin{array}{c}\text { Day } \\
\text { tagged }\end{array}$ \\
\hline STG & 2016 & North & 25 & Sept 25 \\
STG & 2016 & South & 25 & Sept 22, 26 \\
STG & 2019 & South & 33 & Sept 23-25 \\
STG & 2016 & Zapadni & 25 & Sept 27 \\
SNP & 2010 & Polovina Cliffs & 8 & Aug 22 \\
SNP & 2011 & Polovina Cliffs & 10 & Oct 6 \\
SNP & 2012 & Polovina Cliffs & 10 & Sept 29 \\
SNP & 2014 & Polovina Cliffs & 23 & Sept 27, 28 \\
SNP & 2015 & Polovina Cliffs & 1 & Oct 5 \\
SNP & 2016 & Polovina Cliffs & 17 & Oct 4 \\
SNP & 2017 & Polovina Cliffs & 34 & Oct 2,6 \\
SNP & 2019 & Polovina Cliffs & 27 & Sept 29 \\
SNP & 2016 & Zapadni Reef & 25 & Oct 5,6 \\
SNP & 2017 & Zapadni Reef & 36 & Oct 1,4 \\
SNP & 2019 & Zapadni Reef & 25 & Sept 28 \\
\hline
\end{tabular}

Table 2. Duty cycle programming for VHF transmitter flipper tags by year of deployment. Programming is read, for example, as transmitting a signal for 1 min per every $15 \mathrm{~min}$. Dates are mo/d/yr

\begin{tabular}{|lcc|}
\hline Start & Stop & Program \\
\hline $\mathbf{2 0 1 0 - 2 0 1 5}$ & & \\
$07 / 14$ & $11 / 25$ & $1 / 60 \mathrm{~min}$ \\
$\mathbf{2 0 1 6 - 2 0 1 8}$ & & \\
$09 / 15 / 16$ & $12 / 01 / 16$ & $1 / 15 \mathrm{~min}$ \\
$12 / 01 / 16$ & $07 / 06 / 17$ & Off \\
$07 / 06 / 17$ & $08 / 03 / 17$ & $1 / 10 \mathrm{~min}$ \\
$08 / 03 / 17$ & $09 / 14 / 17$ & $1 / 60 \mathrm{~min}$ \\
$09 / 14 / 17$ & $11 / 30 / 17$ & $1 / 15 \mathrm{~min}$ \\
$11 / 30 / 17$ & $07 / 05 / 18$ & Off \\
$07 / 05 / 18$ & $08 / 02 / 18$ & $1 / 10 \mathrm{~min}$ \\
$08 / 02 / 18$ & $09 / 13 / 18$ & $1 / 60 \mathrm{~min}$ \\
$09 / 13 / 18$ & $11 / 29 / 18$ & $1 / 15 \mathrm{~min}$ \\
$11 / 29 / 18$ & $07 / 04 / 19$ & Off \\
$07 / 04 / 19$ & $08 / 01 / 19$ & $1 / 10 \mathrm{~min}$ \\
$08 / 01 / 19$ & $09 / 12 / 19$ & $1 / 60 \mathrm{~min}$ \\
$09 / 12 / 19$ & $11 / 28 / 19$ & $1 / 15 \mathrm{~min}$ \\
$11 / 28 / 19$ & $07 / 02 / 20$ & Off \\
$\mathbf{2 0 1 9}$ & & \\
$07 / 07 / 19$ & $09 / 23 / 19$ & $1 / 10 \mathrm{~min}$ \\
$09 / 24 / 19$ & $12 / 01 / 19$ & $1 / 60 \mathrm{~min}$ \\
\hline
\end{tabular}

lead-acid battery, and a R4520C receiver-datalogger (Advanced Telemetry Systems). Receivers were deployed in the spring of each study year prior to the onset of the breeding and lactation season. Receivers were programmed to scan each frequency for tag transmission signals for $4 \mathrm{~s}$ (detection scan time), dwell an additional $4 \mathrm{~s}$ if a signal was detected to ensure identification of the pulse-code, and store the 
Table 3. Breakdown of mixed effect models used to evaluate rookery-averaged northern fur seal maternal foraging trip duration (MFTD) including data and variables used

\begin{tabular}{|c|c|c|c|c|c|c|}
\hline \multirow{2}{*}{ Model } & \multirow{2}{*}{\multicolumn{2}{|c|}{$\begin{array}{ll} & \text { Data } \\
\text { Rookeries } & \text { Years }\end{array}$}} & \multirow{2}{*}{ Response } & \multirow{2}{*}{$\mathrm{N}$ trips } & \multirow[t]{2}{*}{ Fixed effect } & \multirow[t]{2}{*}{ Random effect } \\
\hline & & & & & & \\
\hline 1 & $\begin{array}{c}\text { North, South, Zapadni, } \\
\text { Polovina Cliffs, Zapadni Reef }\end{array}$ & 2017-2019 & Mean MFTD & 2949 & Year×Rookery & Animal ID \\
\hline 2 & Polovina Cliffs & 2011-2019 & Mean MFTD & 1131 & Year & Animal ID \\
\hline
\end{tabular}

time and identity of each tag detected, signifying the presence of an animal on the rookery. Four reference transmitter tags were placed at fixed locations on STG and SNP Islands to validate proper functioning of the receivers. Data were downloaded periodically from receivers until late fall at the culmination of the lactation season and the onset of the females' winter migration. This typically occurred at the end of November, when all pups on a given rookery had weaned and less than $10 \%$ of all reproductive females were still present. Attendance behaviors were monitored at Polovina Cliffs from 2010-2019, while NFS from all remaining study rookeries were monitored between 2016 and 2019.

For each individual animal, gaps in attendance records at the rookery were assumed to be foraging trips at sea, provided that the difference in time between one recorded transmission and another was at least $1 \mathrm{~d}$ in duration. Maternal females were identified as such based on attendance records characterized by regularly occurring visits to land of consistent duration (reflecting pup demand for milk) across the nursing period, barring the final visit to land. Attendance on land was assumed to represent nursing bouts. Furthermore, maternal records were defined as having foraging trips that progressively increased in duration in a gradual manner across the nursing period and ranged between 1 and $15 \mathrm{~d}$, consistent with historic methods and observations (Gentry \& Holt 1986, Gentry 1998). Small differences in trip duration caused by differences in tag duty cycles among tag deployments $(10,15,60 \mathrm{~min})$ were assumed to be inconsequential. Only data collected from maternal animals with complete records spanning the entire breeding season (approximately 14 July to 13 November) were included in this study. Records collected in the same year an animal was tagged were excluded from the study because tagging occurred mid-season and not at the start of the lactation period. In total, this study includes data collected from 20112019 at Polovina Cliffs and from 2017-2019 at all other rookeries, comprising a longitudinal dataset with repeated yearly measurements for 134 total females. See Table S1 for details on yearly records per female.

Trip durations across a season were averaged by individual within a year. To account for the longer data record at Polovina Cliffs (2011-2019) as compared to all other rookeries (2017-2019), 2 mixed-effect models were considered (Table 3 ). One examined variation in rookery-level averaged MFTD as a function of an interaction between year and rookery with a random effect for individual for all 5 rookeries between 2017 and 2019. Similarly, rookery-level averaged MFTD was examined as a function of year with a random effect for individual for Polovina Cliffs' females between 2011 and 2019. Each model was evaluated using likelihood ratio tests in $\mathrm{R}$ version 4.0.3 (Bates et al. 2014, R Core Team 2020).

\subsubsection{Pup mass}

As a part of a separate investigation into demographic vital rates, large numbers of anonymous (i.e. mother-pup relationships were unknown) female pups from 3 rookeries (South on STG, Polovina Cliffs and Zapadni Reef on SNP) were weighed to the nearest $0.2 \mathrm{~kg}$ using a spring scale (Testa et al. 2018; Table 4) Weighing occurred between 22 September and 6 October each fall from 2009 to 2017, and in 2019 .

Table 4. Number of female northern fur seal pups weighed by study rookery. $(-)$ Data not collected

\begin{tabular}{|lcccccccccccc|}
\hline \multirow{2}{*}{ Rookery } & \multicolumn{10}{|c|}{ Year } & & \\
\cline { 2 - 10 } & 2009 & 2010 & 2011 & 2012 & 2013 & 2014 & 2015 & 2016 & 2017 & 2019 \\
\hline South & 984 & 846 & 889 & 471 & 562 & 461 & 193 & 373 & 496 & 166 \\
Polovina Cliffs & 478 & 99 & 58 & 38 & 161 & 19 & 240 & 101 & 170 & 92 \\
Zapadni Reef & - & 653 & 700 & 562 & 576 & 519 & 624 & 376 & 448 & 232 \\
\hline
\end{tabular}


To control for pup growth across the $15 \mathrm{~d}$ of variation in measurement dates, and a known $3 \mathrm{~d}$ variation in average parturition dates between islands (Gentry 1998), raw masses were adjusted to a common age by fitting a simple linear regression model that incorporated a variable for days before or after 1 October on SNP Island and 28 September on STG. Doing so allowed for an estimation of a mean daily growth rate that was used to adjust the masses to an approximate mean age of $80 \mathrm{~d}$. The mean of rookery mean masses were used as offsets and the regressions were forced through the origin using the following R syntax: $\operatorname{lm}$ (formula = OffsetMass $\sim-1+$ Day + Rookery $\times$ Year). This treats each rookery-year as a factor (29 in total) and fits a common slope to the effect of day (incorporating information from rookeries that were visited more than once in any given year). It assumes that the common (growth) slope applies to all rookery-years, including those that only had 1 measuring date. While small differences in growth rate between rookeries may exist, the potential bias such differences might introduce was judged to be small because the variation in measuring dates $( \pm 7 \mathrm{~d})$ is considerably less than the expected age of the pups $(\sim 80 \mathrm{~d})$. The use of a mass offset by mean mass of all rookery-years allows for statistical testing for differences of each rookery in each year from the mean of all annual rookery masses. This was accomplished by employing a linear model whereby average adjusted pup masses were evaluated as a function of rookery and year.

Simple linear regression was used to evaluate the relationship between adjusted rookery-averaged female pup mass and rookery-averaged MFTD where congruent data existed: i.e. 2011-2017 and 2019 at Polovina Cliffs. For this analysis, MFTD was averaged from onset of the breeding season up until the date pups were weighed. Similar analyses at South and Zapadni Reef could not be undertaken due to smaller pup weight datasets resulting from unforeseen logistical constraints. However, when available, mass and trip duration data from these 2 sites are presented for comparison.

\subsubsection{Pollock and environmental metrics}

Six metrics sourced from publicly available data and reports (Ianelli et al. 2019, Siddon \& Zador 2019) were used to model the relationships between the quality and quantity of pollock, EBS bottom temperatures, and average MFTD. Bottom temperature (metric 1) was used to draw inferences about prey distribution. Because MFTD may reflect caloric intake, quality of prey was assessed using average energy density ( $\mathrm{kJ} \mathrm{g}^{-1}$ ) of age-0 (metric 2$)$, lengthweight residuals of age-1 (fork length $=100-250 \mathrm{~mm}$, metric 3), and length-weight residuals of age-2+ (fork length $>250 \mathrm{~mm}$, metric 4) pollock. Lengthweight residuals are an index of how heavy a fish is per unit body length, an indication of somatic growth and therefore a proxy of body condition (Brodeur et al. 2004, Siddon \& Zador 2019). Abundance (millions) of age-1 (metric 5) and biomass (millions of $t$ ) of age-1+ (metric 6) pollock served as proxies for quantity, or availability to NFS. Metrics 1, 5, and 6 were sourced from, and with methods described by, Ianelli et al. (2019), collected as a part of their efforts to produce robust annual stock assessments through annual summer bottom trawl surveys that occur across the EBS shelf, broadly encompassing NFS foraging habitat. Metrics 2-4 were obtained from, with methods described by, Siddon \& Zador (2019). Data originally presented solely in figures (metrics 2-4 from Siddon \& Zador 2019) were digitized and estimated using WebPlotDigitizer (Rohatgi 2019). Simple linear regression was employed to test the relationships between these metrics of walleye pollock abundance, biomass, and body condition and ocean bottom temperatures with rookery-averaged MFTD. This was only done using the longitudinal MFTD dataset for Polovina Cliffs (2011-2019) because while models examining metrics $1,3,4$, and 6 were technically possible for other rookeries between 2017 and 2019, they would have been based on 3 data points and were therefore deemed to lack sufficient information to be informative and representative. Further, data for metrics 2 and 5 were only collected in 2 and 1, respectively, of the 3 study years (2017-2019) for other rookeries.

\section{RESULTS}

\subsection{Variation in MFTD}

When examining the pattern of change in average MFTD as a function of year and rookery between all rookeries between 2017 and 2019, results of a likelihood ratio test between Model 1 and its reduced model (Table 4) demonstrated that rookery-averaged MFTD varied as a function of an interaction between the 5 rookeries and across years between 2017 and $2019\left(\chi_{8}^{2}=22.26, p=0.0045\right)$. Within a given year, rookery-averaged MFTD was shorter for animals breeding on STG (North, South, and Zapadni rook- 
eries) than for those on SNP Island (Polovina Cliffs and Zapadni Reef; Fig. 2; Table S3). Trip durations were generally greater in 2017 and 2019 than in 2018 but the effect size of year on MFTD varied by rookery.

The much longer longitudinal data record from Polovina Cliffs revealed that over the time period of 2011-2019, rookery-averaged MFTD varied by year (model 2: $\chi^{2}{ }_{8}=35.02, \mathrm{p}<<<0.01$; Fig. 3; Table S3), with trips being shortest during the cold year of 2012, and longest in the warm year of 2019.

\subsection{Pup mass and MFTD}

The grand mean female pup mass at approximately 80 d old spanning 2009-2019 for South, Polovina Cliffs, and Zapadni Reef was $10.89 \pm 0.01 \mathrm{~kg}$ (SE) (range 9.68-11.52 kg) with growth rate estimated at $0.119 \pm 0.014 \mathrm{~kg} \mathrm{~d}^{-1}$. Changes in mass across years were broadly synchronous between rookeries (Fig. 4) but with frequent years in which the average mass of female pups from one rookery deviated substantially from the other 2 (e.g. Polovina Cliffs: 2009 and 2016, South: 2011).

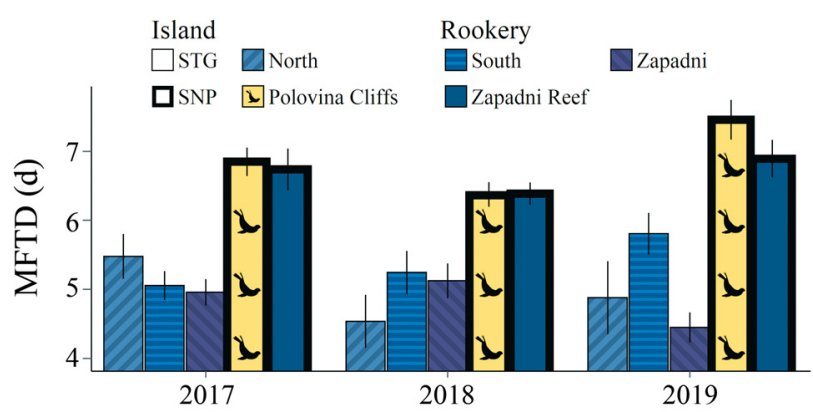

Fig. 2. Average annual maternal foraging trip duration (MFTD , \pm SE) of females with complete records spanning the entire breeding season by rookery and year. STG: St. George Island; SNP: St. Paul Island

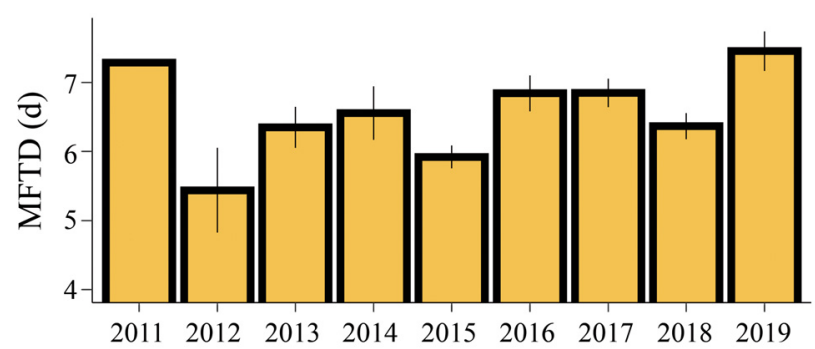

Fig. 3. Average annual maternal foraging trip duration (MFTD, \pm SE) of females from Polovina Cliffs, St. Paul Island. Only females that had complete records spanning the entire breeding season were included
Average female pup mass was negatively correlated with rookery-averaged MFTD through to the date pups were weighed $\left(F_{1,6}=6.81, \mathrm{p}=0.038\right)$, with MFTD explaining $53.95 \%$ of the variation in female pup mass (Fig. 5). On average, female pups were $\sim 0.71 \mathrm{~kg}$ lighter (a $6.52 \%$ reduction of the $10.89 \mathrm{~kg}$ average female mass) for each day rookery-averaged MFTD increased.

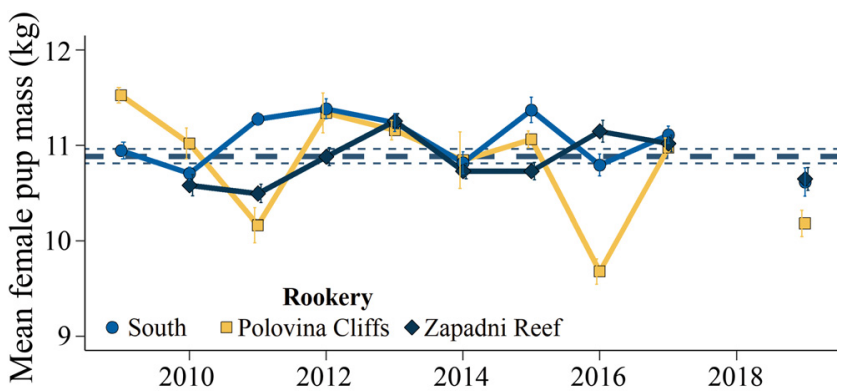

Fig. 4. Average female pup mass $( \pm \mathrm{SE}$, whiskers), corrected for date of weighing, across years at the South rookery (St. George Island), and Polovina Cliff and Zapadni Reef rookeries (St. Paul Island). The heavy horizontal dashed line represents the mean across all females, rookeries, and years with accompanying standard error (light horizontal dashed line)

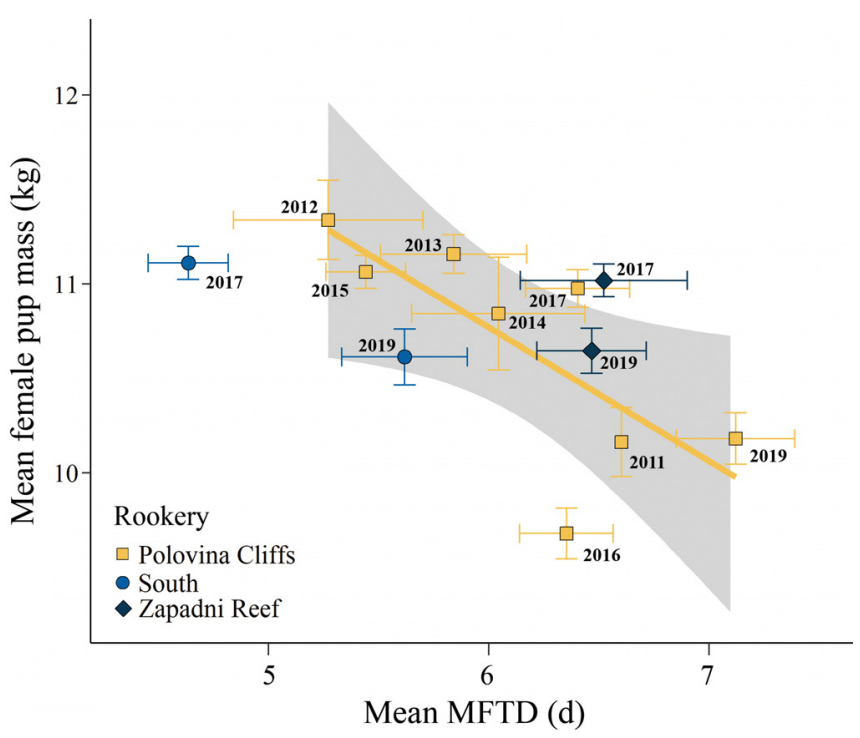

Fig. 5. Relationship between average northern fur seal female pup mass ( $\pm \mathrm{SE}$, through to date of weighing) and mean maternal foraging trip duration $(\mathrm{MFTD}, \pm \mathrm{SE}$ ) for 3 rookeries: South on St. George Island, and Polovina Cliffs and Zapadni Reef on St. Paul Island. Shading: $95 \%$ CI. We only had sufficient data to regress average female pup mass against mean annual maternal foraging trip duration through the date pups were weighed at Polovina Cliffs. Values from other rookeries are presented for cursory comparisons and are not represented in the regression line 


\subsection{Interannual variation in MFTD in relation to temperature and pollock quantity and quality}

The average bottom temperature for the Bering Sea over the period $1982-2019$ was $2.57^{\circ} \mathrm{C}$ (Ianelli et al. 2019), and many study years were characterized by above-average values (range $0.87-4.84^{\circ} \mathrm{C}_{i}$ Ianelli et al. 2019). Rookery-averaged MFTD increased by $0.34 \mathrm{~d}$ per $1^{\circ} \mathrm{C}$ increase in bottom temperature $\left(F_{1,7}=\right.$ $4.28, \mathrm{p}=0.077$; Fig. $6 \mathrm{~A}$ ) at the $\alpha=0.10$ level.
Energy density of age- 0 pollock averaged $4.36 \pm$ $0.17 \mathrm{~kJ} \mathrm{~g}^{-1}$ (range 3.77-5.02) between 2011 and 2019 and was lower in warm years compared to cold years (Siddon \& Zador 2019). However, there was no correlation between energy density of age-0 pollock and rookery-averaged MFTD for Polovina Cliffs females $\left(F_{1,5}=0.27, \mathrm{p}=0.62\right.$; Fig. $\left.6 \mathrm{~B}\right)$.

The body condition of age-1 pollock (lengthweight residuals) ranged from -0.055 to 0.062 between 2011 and 2019 and was generally positive in
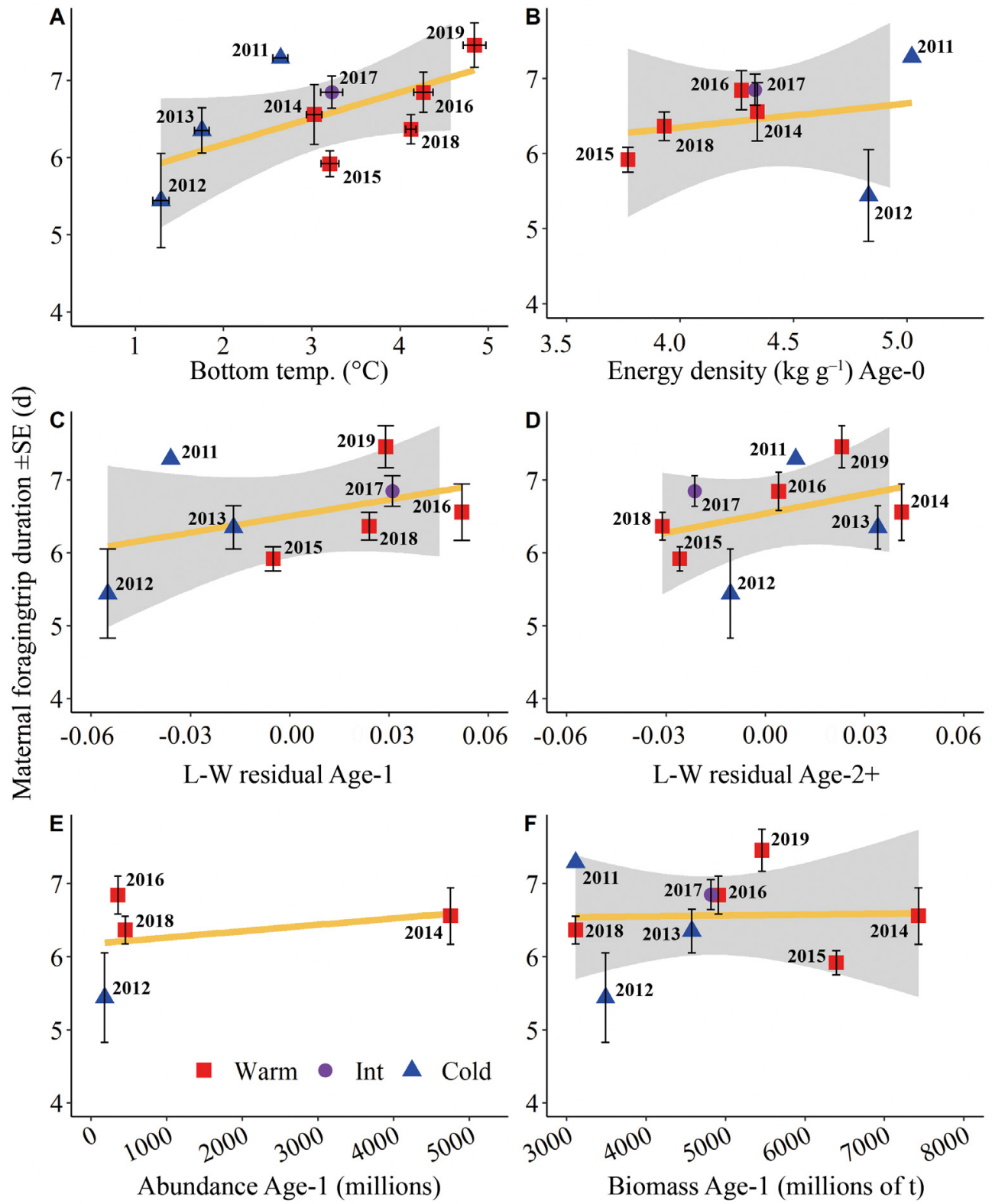

Biomass Age-1 (millions of $\mathrm{t}$ )

Fig. 6. Regression of mean annual maternal foraging trip duration for Polovina Cliffs northern fur seal females as a function of various environmental and prey (walleye pollock) metrics with data point colors denoting cold $\left(<2.57^{\circ} \mathrm{C}\right)$, intermediate, or warm $\left(>2.57^{\circ} \mathrm{C}\right)$ temperature conditions as defined by Ianelli et al. (2019) and Siddon \& Zador (2019). Whiskers denote standard errors. Errors were unknown for some independent variables because values were estimated from publicly available figures (Ianelli et al. 2019, Siddon \& Zador 2019). L-W: length to weight relationship 
recent 'warm' years, but down from 2016 values (Siddon \& Zador 2019). In contrast, body condition of age$2+$ pollock was lower in warm years with lengthweight residuals ranging between -0.031 and 0.041 from 2011 to 2019 (Siddon \& Zador 2019). However, there was no correlation between body condition of age-1 $\left(F_{1,7}=1.68, \mathrm{p}=0.24\right)$ or age- $2+\left(F_{1,7}=1.09, \mathrm{p}=\right.$ 0.33 ) pollock and MFTD for females from Polovina Cliffs across the study period (Fig. 6C,D).

No relationship existed between observed variation in age- 1 pollock abundance (average $1.43 \times 10^{9}$ fish across the EBS survey grid, range $1.77 \times 10^{9}$ to $4.75 \times 10^{9}$, Ianelli et al. 2019) and rookery-averaged MFTD for Polovina Cliffs females between 2011 and $2019\left(F_{1,2}=0.23, \mathrm{p}=0.68\right.$; Fig. 6E). Moreover, although biomass of age-1+ pollock generally increased in 'warm' years (average 4702.8 million $\mathrm{t}$ across the EBS survey grid, range 3112-7429; Ianelli et al. 2019), there was no relationship with trip duration $\left(F_{1,7}=0.01, \mathrm{p}=0.94\right.$; Fig. $\left.6 \mathrm{~F}\right)$.

\section{DISCUSSION AND CONCLUSIONS}

\subsection{Variability in MFTD}

Rookery-averaged MFTD was generally shorter for animals breeding on STG than for those on SNP but did not differ amongst animals from different rookeries on the same island, a finding previously reported (e.g. Gentry \& Holt 1986, Gentry 1998, Kuhn et al. 2014). These trends in rookery-averaged MFTD are consistent with, and at least partially explained by, the transit times required to reach the varying foraging habitats associated with rookery complexes, as determined by telemetry tracking studies (Gudmundson et al. 2006, Benoit-Bird et al. 2013, Kuhn et al. 2014). For example, the foraging habitats for females from STG are closer to the rookeries, smaller in extent, and straddle the continental shelf break, whereas SNP foraging grounds are likely associated with longer travel times because they are larger and centered more directly over the continental shelf (Robson et al. 2004, Zeppelin \& Ream 2006, Call et al. 2008). The relationship between MFTD and distance to foraging locations is consistent with other species as well. For example, Antarctic fur seal females from 2 rookeries on South Georgia Island that forage in overlapping habitats do not have significantly different MFTDs (Doidge et al. 1986). Prior work by BenoitBird et al. (2013) examined the patchiness of forage fish distribution and the movements of NFS and concluded that time spent within forage patches by fur seals was relatively constant within each trip, and that variation in MFTD was largely a function of transit times to and from the source rookery, and between forage patches. Annual deviations in MFTD (as was observed at Polovina Cliffs) may therefore be indicative of the differential impact that foraging conditions have on the behavior of females between rookeries, as opposed to the differences in MFTD observed between islands. Similar patterns have been seen in other central-place foragers: trip durations measured across 5 breeding seasons of macaroni penguins Eudyptes chrysolophus were significantly longer when local prey density was low (Horswill et al. 2017). The penguins foraged further from their colony, presumably to reach more distant foraging grounds, and resulted in marked decreases in fledgling weights (Horswill et al. 2017).

\subsection{Pup mass and MFTD}

Although direct mother-pup relations were unknown, rookery-averaged MFTD appears to be a good indicator of the foraging conditions experienced by lactating females, as there was a negative relationship between average female pup mass and MFTD. This may indicate that adult females that take longer to obtain needed energy resources while at sea are unable to compensate for the longer times between feedings by providing more, or more energy-rich, milk to their pups upon return. Pups that fast for a longer period between feedings grow more slowly and are likely weaned at lower mass and/or with reduced energy reserves (Lunn et al. 1993). While not yet demonstrated for female pups, it is plausible that mass would correlate with survival. This is the case for male NFS pups (Baker \& Fowler 1992), but these effects are most notable when weaning masses are significantly lower than average values observed in this study. For example, the mean masses of females at our sites were generally higher than the long-term averages $(10.1 \mathrm{~kg})$ reported for female NFS on San Miguel Island, CA (Orr et al. 2016, 2018). Daily growth rates were used to standardize those measurements to 1 October, but birthing in California probably occurs $7 \mathrm{~d}$ earlier (Orr et al. 2016). The difference is therefore likely underestimated. While analysis of pup masses in this study on the Pribilof Islands showed below-average values in some years at some rookeries, these weights were substantially higher than those at San Miguel Island in years where the demographic effects of strong El 
Niño events were evident. That is, San Miguel pups were $>2 \mathrm{~kg}$ lighter, or nearly $20 \%$, than average as a result of reduced prey availability to mothers (Orr et al. 2016, 2018). In this study, fewer than $2 \%$ of pups weighed on the Pribilof Islands were more than $2 \mathrm{~kg}$ below the average weaning mass, even in years where the longest MFTDs were observed. Thus, while the negative relationship with MFTD observed here may suggest a potential mechanism for varying pup mass that in turn could impact survival, pup masses across the study period do not appear to vary significantly enough to the point of demographic relevance. In other words, reduced body condition resulting from increased MFTD may decrease the survival probability of individual pups but too few were observed with extreme reductions in mass for this relationship to help explain the population decline (Towell et al. 2019) generally experienced by the Pribilof NFS population across the study period.

Further complicating our ability to draw conclusions between the observed link between MFTD and pup mass with demographic consequences is the fact that the relationship between weaning mass and survival may not be linear, as is the case in other pinnipeds. For example, pup survival varies as a polynomial function of weaning mass for southern elephant seals Mirounga leonina (McMahon et al. 2003), and in an asymptotic fashion in harbor seal Phoca vitulina (Harding et al. 2005). It may be that the variation in late-summer pup mass that in this study was correlated with variation in MFTD was not yet at a threshold large enough to evoke populationlevel consequences, but instead within the range that could be accommodated through behavioral plasticity postweaning. Still, the relatively strong correlation between pup mass and MFTD means that if sufficiently unfavorable conditions occurred in the EBS to affect the quality, quantity, and/or distribution of resources significantly enough that pup survival were impacted, MFTD would also be detectably increased, representing an index of juvenile survival. This is particularly important with respect to changes in the cold pool in the EBS, a major driver of productivity and distribution of prey species, which continues to recede north in accordance with a rapidly warming environment (Ianelli et al. 2019, Thoman \& Walsh 2019). If we are indeed at the beginning of a major ecosystem shift in the Bering Sea (Reum et al. 2020), rookery-averaged MFTD is a promising metric for tracking broad-scale environmental changes and understanding the subsequent consequences to NFS.

\subsection{MFTD as it relates to foraging conditions}

Our results suggest that rookery-averaged MFTD can act as an indicator of environmental and foraging conditions of the local marine habitat, namely as it relates to prey distribution. We were surprised that the number of age-1 pollock (as determined through groundfish trawl surveys; Ianelli et al. 2019, Siddon \& Zador 2019) did not correlate with MFTD. In contrast, Sterling (2009) demonstrated a negative correlation between estimated numbers of age-1-5 pollock and MFTD; however, the variation in trip duration (Peterson 1965, Loughlin et al. 1987, Goebel 2002) between the years observed (1963-1995) was greater than the variation observed across our study period. Similarly, there was no relationship with biomass of age-1+ pollock. This may be because there was an adequate quantity of forage available to NFS across the whole of the EBS during the study period, in which case no shift in behavior would be necessary. To that point, the biomass of age-1+ pollock was generally above average in the warm conditions that were common during this study (Ianelli et al. 2019). Warm years were also associated with positive (though decreased, see Fig. 69 in Siddon \& Zador 2019) body condition (length-weight residuals) in age-1 pollock, suggesting that fewer age1 fish would be needed to meet NFS caloric demands. However, the energy density of age- 0 pollock is lower in warm years, suggesting that foraging females would have needed to capture more age-0 fish in order to return ashore with similar calories. While the reduced caloric density in the preferred age-0 pollock may have been expected to lead to increased MFTD, it may be that females could offset reductions in caloric value of age- 0 fish by foraging more intensely on age$1+$ fish, or other species, if more abundant.

Alternatively, the absence of any relationship between average MFTD and single metrics of prey condition examined here suggest that the quality of the overall preyfield (which consists of a mixture of different aged pollock as well as other species) has not varied significantly enough in aggregate across the study period so as to prevent foraging NFS females from meeting their energetic demands. This is despite varying trends in these metrics with changes in climate described above. That is not to say females are not responding behaviorally to these shifts to meet their needs, as may be evidenced by the relationship between rookery-averaged MFTD and average bottom temperature described below.

Trips were longer in years when ocean bottom temperatures were warmer in the areas around the rookeries. In the EBS, many species, including pollock, 
make latitudinal shifts northward with warming bottom temperatures (Kotwicki et al. 2005, Mueter \& Litzow 2008). It is plausible that NFS may shift diet in response to declines in regional abundance of pollock to less-preferred alternative species, judged as such based on their presence in NFS diet (Gudmundson et al. 2006). Presumably NFS have previously maximized their foraging efficiency and this shift would cause increases in MFTD resulting from changes in caloric value, distribution, density, and depth of alternative prey sources. Alternatively, NFS may pursue pollock northward, increasing MFTD by way of increased transit time. This suggests that patterns in rookeryaveraged MFTD we observed may reflect, at least in part, prey distribution. If NFS-preferred prey distribution tracks with the drastically shrinking and receding cold pool (Stabeno \& Bell 2019, Danielson et al. 2020), NFS would be forced to travel extended distances north in pursuit during increasingly frequent warm periods. In support of this hypothesis were the results of a concurrent project examining foraging bioenergetics that suggested SNP females had difficulty finding food in close proximity to the rookery (Kuhn et al. 2019). Furthermore, Eisner et al. (2020) demonstrated that adult pollock concentrated north of St. Lawrence Island in warm years (2017-2019), likely as a redistribution from the more southern regions of the EBS. Adult and juvenile pollock have also been observed in high densities as far north as the southern Chukchi Sea during anomalously warm years (Orlov et al. 2019, Eisner et al. 2020), and, although pollock are increasingly demersal with age (Ianelli et al. 2019), the age classes preferred by NFS females (age-0/1) are frequently found in large numbers near the bottom (Ianelli et al. 2019). Thus, in combination, these studies suggest that bottom temperatures are a good proxy for the relative distribution of pollock in size classes preferred by foraging NFS females.

However, because these conclusions are limited to the perspective (i.e. foraging behavior and location) of 1 rookery (Polovina Cliffs, 2011-2019), further research should validate the method and conclusions for additional rookeries. A complete evaluation of the underlying causes of any shift in MFTD by NFS requires information on the behavioral metric itself (MFTD), the location of prey, and any shifts in diet. Notwithstanding, the heavy dependence of Pribilof NFS on pollock during the lactation period and the correlation between bottom temperatures and MFTD suggest that this behavioral metric may provide a rough index of shifts in prey distribution, even in the absence of extensive (and expensive) ship-based surveys.
Acknowledgements. We acknowledge that this work took place on traditional native Unangan lands. Staff of the National Marine Fisheries Service, Alaska Fisheries Science Center, Alaska Ecosystems Program (Tom Gelatt, Jeremy Sterling, Carey Kuhn, Rolf Ream) and the Alaska Regional Office (Mike Williams) provided indispensable support in and out of the field with animal capture and handling, logistics, and data analysis. Additional field support was provided by our tribal partners at the Ecosystem Conservation Offices of St. George and St. Paul, particularly Dennis Lekanof, Veronica Padula, Paul Melovidov, Aaron Lestenkof, Lauren Divine, and Pamela Lestenkof. Funding was provided in large part by the Pollock Conservation Cooperative Research Center with additional funding provided by the Alaska Regional Office, the National Science Foundation (NSF) Graduate Research Fellowship, AlaskaINBRE, and the LGL Graduate Research Award. We are exceedingly grateful for the time and resources our collaborators have provided to make this project successful. This material is based upon work supported in part by the NSF Graduate Research Fellowship Program (G.B.M.) and while serving at the NSF (J.M.B.). Any opinions, findings, and conclusions or recommendations expressed in this material are those of the authors and do not necessarily reflect the views of the NSF nor the authors' affiliated institutions.

\section{LITERATURE CITED}

Baker JD, Fowler CW (1992) Pup weight and survival of northern fur seals Callorhinus ursinus. J Zool (Lond) 227: 231-238

* Bates D, Mächler M, Bolker B, Walker S (2014) Fitting linear mixed-effects models using lme4. J Stat Softw 67:1-48

* Beauplet G, Dubroca L, Guinet C, Cherel Y, Dabin W, Gagne C, Hindell M (2004) Foraging ecology of subantarctic fur seals Arctocephalus tropicalis breeding on Amsterdam Island: seasonal changes in relation to maternal characteristics and pup growth. Mar Ecol Prog Ser 273:211-225

Benoit-Bird KJ, Battaile BC, Nordstrom CA, Trites AW (2013) Foraging behavior of northern fur seals closely matches the hierarchical patch scales of prey. Mar Ecol Prog Ser 479:283-302

Boyd IL, Arnould JPY, Barton T, Croxall JP (1994) Foraging behavior of Antarctic fur seals during periods of contrasting prey abundance. J Anim Ecol 63:703-713

*Boyd I (1999) Foraging and provisioning in Antarctic fur seals: interannual variability in time-energy budgets. Behav Ecol 10:198-208

Brodeur RD, Fisher JP, Teel DJ, Emmett RL, Casillas E, Miller TW (2004) Juvenile salmonid distribution, growth, condition, origin, and environmental and species associations in the Northern California Current. Fish Bull 102: $25-46$

* Call KA, Ream RR, Johnson D, Sterling JT, Towell RG (2008) Foraging route tactics and site fidelity of adult female northern fur seal (Callorhinus ursinus) around the Pribilof Islands. Deep Sea Res II 55:1883-1896

Clutton-Brock T, Guinness F, Albon S (1982) Red deer: behavior and ecology of two sexes. University of Chicago Press, Chicago, IL

Conner J, Lauth RR (2016) Results of the 2013 Eastern Bering Sea continental shelf bottom trawl survey of groundfish and invertebrate resources. US Department of Commerce, NOAA Tech Memo NMFS-AFSC-331 
Croxall J, Prince P (1979) Antarctic seabird and seal monitoring studies. Polar Rec 19:573-595

*Danielson SL, Ahkinga O, Ashjian C, Basyuk E and others (2020) Manifestation and consequences of warming and altered heat fluxes over the Bering and Chukchi Sea continental shelves. Deep Sea Res II 177:104781

DeLong R, Antonelis G (1991) Impact of the 1982-1983 El Niño on the northern fur seal population at San Miguel Island, California. In: Trillmich F, Ono K (eds) Pinnipeds and El Niño. Springer-Verlag, Berlin, p 74-83

Doidge D, Croxall J, Baker J (1984a) Density-dependent pup mortality in the Antarctic fur seal (Arctocephalus gazella) at South Georgia. J Zool 202:449-460

* Doidge D, Croxall J, Ricketts C (1984b) Growth rates of Antarctic fur seal (Arctocephalus gazella) pups at South Georgia. J Zool 203:87-93

Doidge D, McCann T, Croxall J (1986) Attendance behavior of Antarctic fur seals. In: Gentry R, Kooyman G (eds) Maternal strategies on land and at sea. Princeton University Press, Princeton, NJ, p 102-114

Eisner LB, Zuenko YI, Basyuk EO, Britt LL and others (2020) Environmental impacts on walleye pollock (Gadus chalcogrammus) distribution across the Bering Sea shelf. Deep Sea Res II 181-182:104881

Elorriaga-Verplancken FR, Sierra-Rodríguez GE, RosalesNanduca H, Acevedo-Whitehouse K, Sandoval-Sierra J (2016) Impact of the 2015 El Niño-Southern Oscillation on the abundance and foraging habits of Guadalupe fur seals and California sea lions from the San Benito Archipelago, Mexico. PLOS ONE 11:e0155034

Gentry R (1998) Behavior and ecology of the northern fur seal. Princeton University Press, Princeton, NJ

Gentry R, Holt J (1986) Attendance behavior of northern fur seals. In: Gentry R, Kooyman G (eds) Fur seals: maternal strategies on land and at sea. Princeton University Press, Princeton, NJ, p 41-60

Goebel M (2002) Northern fur seal lactation, attendance and reproductive success in two years of contrasting oceanography. PhD thesis, University of California Santa Cruz

Grant PR, Grant BR (2002) Unpredictable evolution in a 30year study of Darwin's finches. Science 296:707-711

Gudmundson CJ, Ream RR, Zeppelin TK (2006) Application of two methods for determining diet of northern fur seals (Callorhinus ursinus). Fish Bull 104:445-455

Harding K, Fujiwara M, Axberg Y, Härkönen T (2005) Massdependent energetics and survival in harbour seal pups. Funct Ecol 19:129-135

Holsman K, Hollowed A, Ito S, Bograd S and others (2018) Climate change impacts, vulnerabilities and adaptations: North Pacific and Pacific Arctic marine fisheries. In: Barange $\mathrm{M}$, Bahri $\mathrm{T}$, Beveridge MCM, Cochrane KL, Funge-Smith, Poulain F (eds) Impacts of climate change on fisheries and aquaculture: synthesis of current knowledge, adaptation and mitigation options. FAO Fisheries and Aquaculture Tech Pap 627. FAO, Rome, p 113-138

Horswill C, Trathan PN, Ratcliffe N (2017) Linking extreme interannual changes in prey availability to foraging behaviour and breeding investment in a marine predator, the macaroni penguin. PLOS ONE 12:e0184114

Ianelli JN, Barbeaux S, Honkalehto T, Kotwicki S, Aydin K, Williamson $N$ (2019) Assessment of the walleye pollock stock in the Eastern Bering Sea. www.afsc.noaa.gov/ REFM/docs/2010/EBSpollock.pdf

Kotwicki S, Buckley TW, Honkalehto T, Walters G (2005) Variation in the distribution of walleye pollock (Theragra chalcogramma) with temperature and implications for seasonal migration. Fish Bull 103:574-587

*Kuhn CE, Ream RR, Sterling JT, Thomason JR, Towell RG (2014) Spatial segregation and the influence of habitat on the foraging behavior of northern fur seals (Callorhinus ursinus). Can J Zool 92:861-873

Kuhn CE, Sterling JT, Zeppelin TK (2015) Linking northern fur seal behavior with prey distributions: the impact of temporal mismatch between predator studies and prey surveys. Anim Biotelem 3:26

Kuhn C, Sterling J, McHuron E (2019) Contrasting trends in northern fur seal foraging effort between St. Paul and Bogoslof Islands: 2019 preliminary results. In: Siddon E, Zador S (eds) Ecosystem status report 2019: Eastern Bering Sea, stock assessment and fishery evaluation report. North Pacific Fishery Management Council, Anchorage, $\mathrm{AK}, \mathrm{p} 30-32$

Kotze HK, Tittensor DP, Bryndum-Buchholz A, Eddy TD and others (2019) Global ensemble projections reveal trophic amplification of ocean biomass declines with climate change. Proc Natl Acad Sci USA 116:12907-12912

Loughlin T, Bengston J, Merrick R (1987) Characteristics of feeding trips of female northern fur seals. Can J Zool 65: 2079-2084

* Lunn NJ, Boyd IL, Barton T, Croxall JP (1993) Factors affecting the growth rate and mass at weaning of Antarctic fur seals at Bird Island, South Georgia. J Mammal 74: 908-919

*Massardier-Galatà L, Morinay J, Bailleul F, Wajnberg E, Guinet C, Coquillard P (2017) Breeding success of a marine central place forager in the context of climate change: a modeling approach. PLOS ONE 12:e0173797

McMahon C, Burton H, Bester M (2003) A demographic comparison of two southern elephant seal populations. J Anim Ecol 72:61-74

* Merrick RL, Loughlin TR (1997) Foraging behavior of adult female and young-of-the-year Steller sea lions in Alaskan waters. Can J Zool 75:776-786

Mueter FJ, Litzow MA (2008) Sea ice retreat alters the biogeography of the Bering Sea continental shelf. Ecol Appl 18:309-320

* Okkonen SR, Schmidt GM, Cokelet ED, Stabeno PJ (2004) Satellite and hydrographic observations of the Bering Sea 'Green Belt'. Deep Sea Res II 51:1033-1051

Orian G, Pearson N (1979) On the theory of central place foraging. In: Horn D, Mitchel R, Stairs G (eds) An analysis of ecological systems. Ohio State University Press, Columbus, OH, p 154-177

Orlov AM, Benzik AN, Vedishcheva EV, Gafitsky SV and others (2019) Fisheries research in the Chukchi sea at the RV 'Professor Levanidov' in August 2019: some preliminary results. Trudy VNIRO 178:206-220

Orr AJ, Melin SR, DeLong RL (2016) Status of the California stock of northern fur seals, 2013-2014. In: Testa JW (ed) Fur seal investigations, 2013-14. US Department of Commerce, NOAA Tech Memo NMFS-AFSC-316, p 51-76

Orr AJ, Melin SR, DeLong RL (2018) Status of the California stock of northern fur seals, 2015-2016. In: Testa JW (ed) Fur seal investigations, 2015-2016. NOAA Tech Memo NMFS-AFSC-375, p 36-55

Peterson R (1965) Behavior of the northern fur seal. PhD thesis, Johns Hopkins University, Baltimore, MD

R Core Team (2020) R: a language and environment for statistical computing. R Foundation for Statistical Computing, Vienna 
Reum JCP, Blanchard JL, Holsman KK, Aydin K and others (2020) Ensemble projections of future climate change impacts on the Eastern Bering Sea food web using a multispecies size spectrum model. Front Mar Sci 7:124

Robson BW, Goebel ME, Baker JD, Ream RR and others (2004) Separation of foraging habitat among breeding sites of a colonial marine predator, the northern fur seal (Callorhinus ursinus). Can J Zool 82:20-29

Rohatgi A (2019) WebPlotDigitizer. San Francisco, CA. https://automeris.io/WebPlotDigitizer/

Saraux C, Robinson-Laverick SM, Le Maho Y, Ropert-Coudert Y, Chiaradia A (2011) Plasticity in foraging strategies of inshore birds: how little penguins maintain body reserves while feeding offspring. Ecology 92:1909-1916

Siddon E, Zador S (eds) (2019) Ecosystem status report 2019. Eastern Bering Sea. North Pacific Fishery Management Council, Anchorage, AK. https://access.afsc.noaa.gov/ REFM/REEM/ecoweb/pdf/2019EBSecosys.pdf

Sigler MF, Napp JM, Stabeno PJ, Heintz RA, Lomas MW, Hunt GL Jr (2016) Variation in annual production of copepods, euphausiids, and juvenile walleye pollock in the southeastern Bering Sea. Deep Sea Res II 134:223-234

Springer AM, Ream RR, Iverson SJ (2008) Seasonal foraging strategies and consequences for northern fur seals at colonies with opposite population trends - Year 2. Consequences of Fur Seal Foraging Strategies (COFFS). North Pacific Research Board Final Report Project 514. https://workspace.aoos.org/files/2580819/514_Final\%20 report.pdf? source $=$ catalog \& portalId $=92$

Stabeno PJ, Bell SW (2019) Extreme conditions in the Bering Sea (2017-2018): record-breaking low sea-ice extent. Geophys Res Lett 46:8952-8959

Editorial responsibility: Peter Corkeron,

Woods Hole, Massachusetts, USA

Reviewed by: M. Horning and 2 anonymous referees
Sterling JT (2009) Northern fur seal foraging behaviors, food webs, and interactions with oceanographic features in the eastern Bering Sea. PhD dissertation, University of Washington, Seattle, WA

Taylor PC, Cai M, Hu A, Meehl J, Washington W, Zhang GJ (2013) A decomposition of feedback contributions to polar warming amplification. J Clim 26:7023-7043 Testa JW (ed) (2018) Fur seal investigations, 2015-2016. US Department of Commerce, NOAA Tech Memo NMFSAFSC-375, www.afsc.noaa.gov/Publications/AFSC-TM/ NOAA-TM-AFSC-375.pdf

Thoman R, Walsh J (2019) Alaska's changing environment: documenting Alaska's physical and biological changes through observations. International Arctic Research Center, University of Alaska, Fairbanks, AK

Towell R, Ream R, Sterling J, Bengtson J, Williams M (2019) 2018 northern fur seal pup production and adult male counts on the Pribilof Islands, Alaska. Alaska Fisheries Science Center, Marine Mammal Laboratory, Seattle, WA

*Walsh JE (2014) Intensified warming of the Arctic: causes and impacts on middle latitudes. Global Planet Change 117:52-63

Weimerskirch H (2018) Linking demographic processes and foraging ecology in wandering albatross - conservation implications. J Anim Ecol 87:945-955

Z Zeppelin TK, Orr AJ (2010) Stable isotope and scat analyses indicate diet and habitat partitioning in northern fur seals Callorhinus ursinus across the eastern Pacific. Mar Ecol Prog Ser 409:241-253

Zeppelin TK, Ream RR (2006) Foraging habitats based on the diet of female northern fur seals (Callorhinus ursinus) on the Pribilof Islands, Alaska. J Zool 270:565-576

Submitted: September 23, 2020

Accepted: March 11, 2021

Proofs received from author(s): May 13, 2021 